\title{
DE ONDERMIJNING VAN FORT ORANJE DOOR DE CLAESGUT OP ST. EUSTATIUS
}

Conserveringsplan voor het eiland Sint Eustatius, door H.J.F. de Roy van Zuydewijn, Delft, maart 1974, 38 blz. gestencild met 5 platen buiten de tekst, geïll. omslag, diverse losse kaarten.

Dit Conserveringsplan - onderdeel van een afstudeerproject voor bouwkundig ingenieur aan de T.H. te Delft - is het eerste resultaat van een door Sticusa gefinancierd project, waarin door twee studenten bouwkunde uit Delft en twee studenten kunsthistorie uit Utrecht, in september en oktober 1972, gegevens werden verzameld voor het opstellen van een integraal conserveringsplan voor historische gebouwen en ruïnes op St. Eustatius.

Nadat in de eerste drie hoofdstukken (p. 4-13) het belang van de historische monumenten voor St. Eustatius wordt aangetoond, volgen een aantal aanbevelingen welke het behoud van deze monumenten ten doel hebben. Hierbij worden onderscheiden: a) twee grote en een aantal kleine natuurbeschermingsgebieden waarin bouwactiviteiten ontoelaatbaar worden geacht; b) een drietal zônes van toeristische ontwikkeling in de 1ste, 2de en 3de graad, zoals ook op een Overzichtskaart van het Bestemmingsplan (1: 10.000) staat aangegeven (Fig. 1).

Vervolgens komen de bouwkundige maatregelen en bestemmingen aan de orde, en het instellen van een monumentenlijst. Een Bestemmingsplan Oranjestad (1 : 5.000) toont ons hoe ir. De Roy van Zuydewijn het Downtown en Uptown van de toekomst zou willen zien.

Het is opvallend met hoe weinig woorden in dit rapport een indrukwekkend documentatiemateriaal wordt ingeleid, met voorbijgaan van veel geschriften welke in dit verband als van weinig waarde werden beschouwd. Zes stedebouwkundige documentaties, 6 kaarten met bestemmingsplannen en 14 opmetingen van monumenten vormen zeker geen gering resultaat van een korte uitzending als deze, waarbij ons nog veel meer resultaten worden beloofd.

Een bijzondere plaats in dit verslag neemt de Claesgut in - een ravijn tussen het Fort Oranje en de R.K. Kerk dat op de kaarten met een vet uitroepteken als gevarenzône is aangeduid (Fig. 2-6).

Wie langs het Old Gin House door de droge bedding van de 


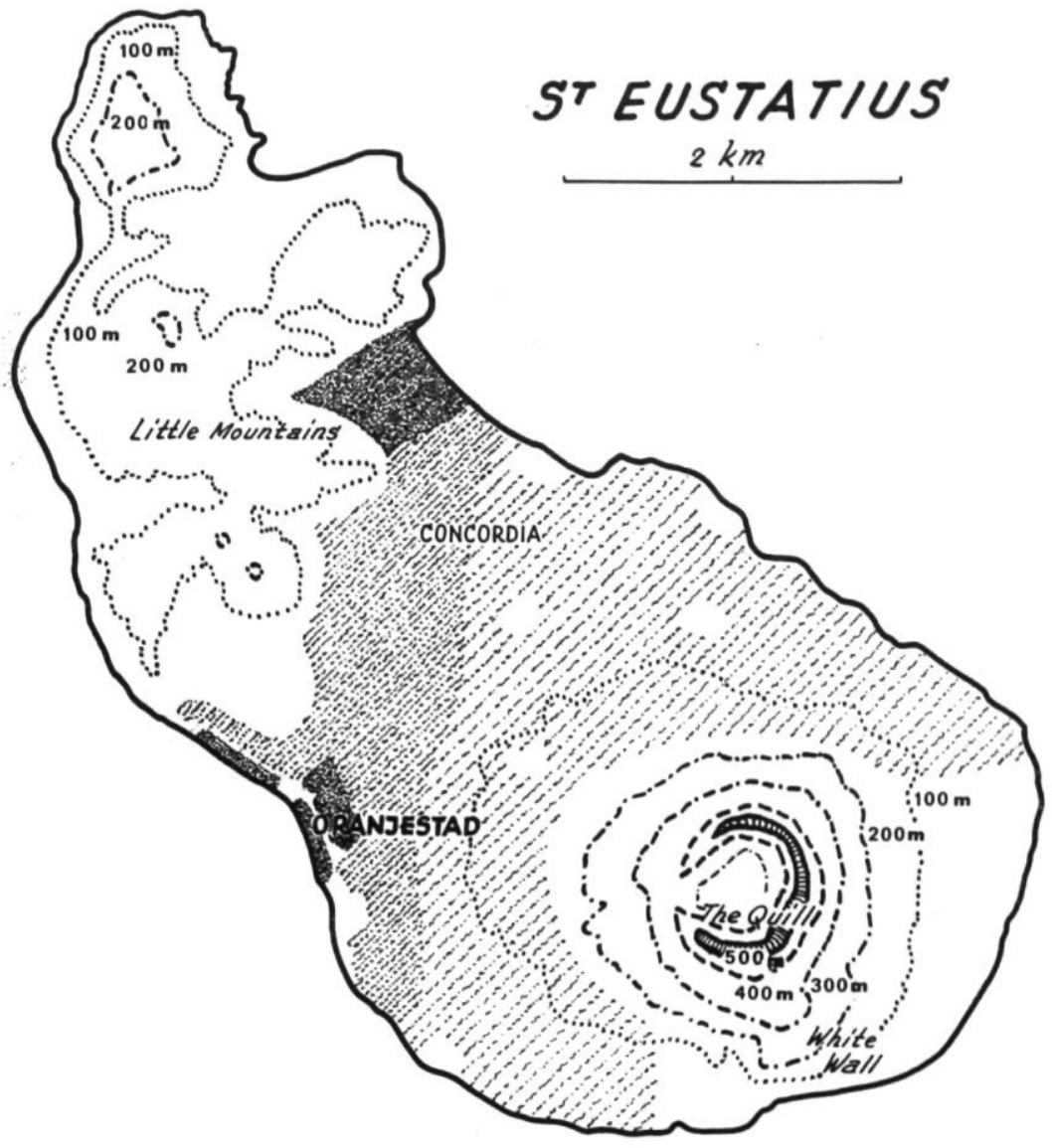

Fig. 1. Het bestemmingsplan voor St. Eustatius zoals de Roy van Zuydewijn zich dit in grote lijnen had gedacht. - A. (wit) Twee grote natuurgebieden, de Quill en de Little Mountains, plus nog een aantal kleinere terreinen in de omgeving van ruïnes en landhuizen, en langs de westkust bij Oranjestad, waar iedere vorm van bouwactiviteit ontoelaatbaar wordt geacht. - B. (licht en donker gearceerd) Twee zones van meer- en minder-beperkte toeristische ontwikkeling, waar een bescheiden bouwactiviteit is toegestaan mits rekening wordt gehouden met de sfeer van het eiland. - C. (zwartig) Een drietal zones van primaire toeristische ontwikkeling, Zeelandia, gebied rondom Fort Oranje, en de voormalige Benedenstad. 


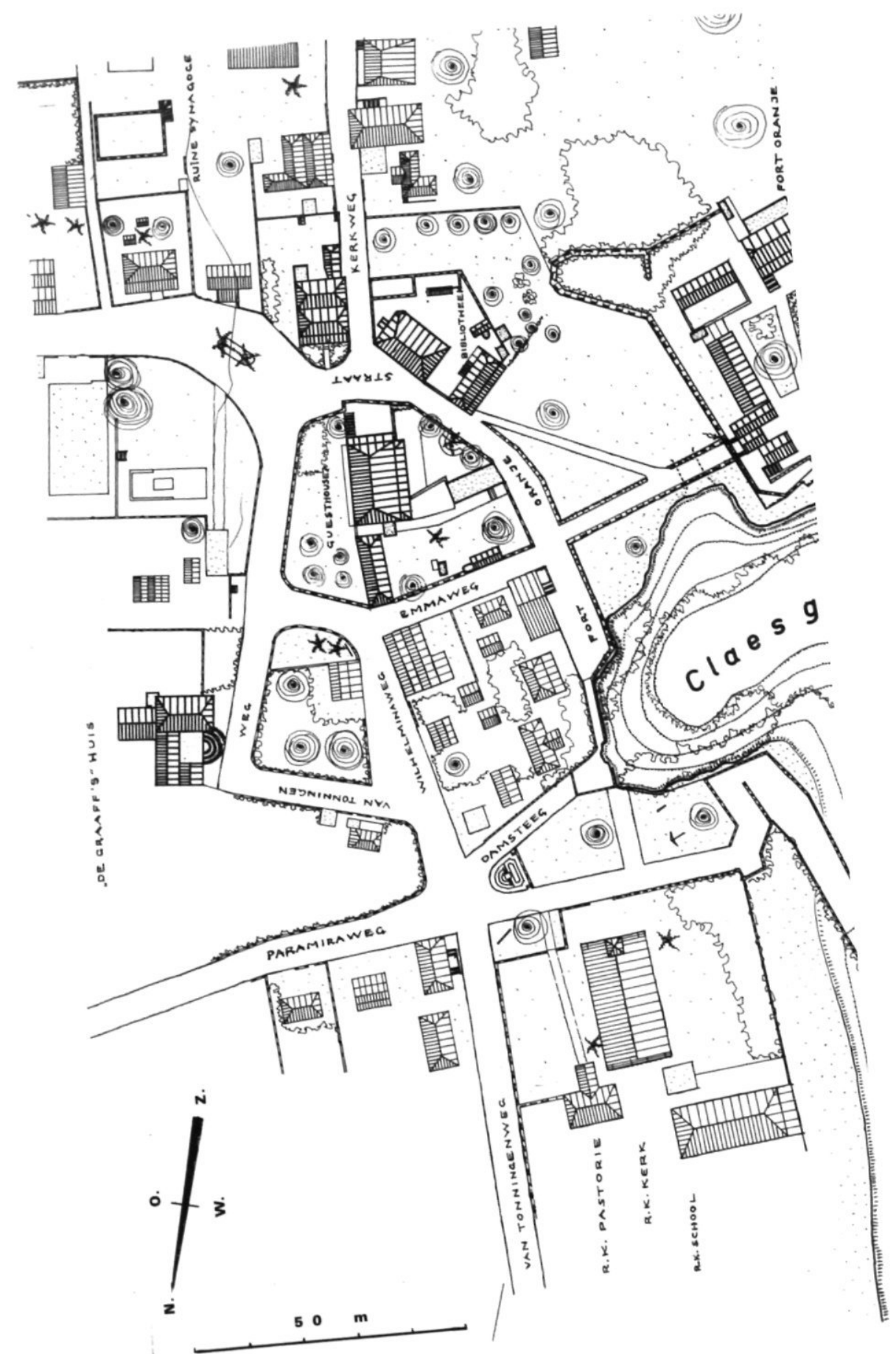



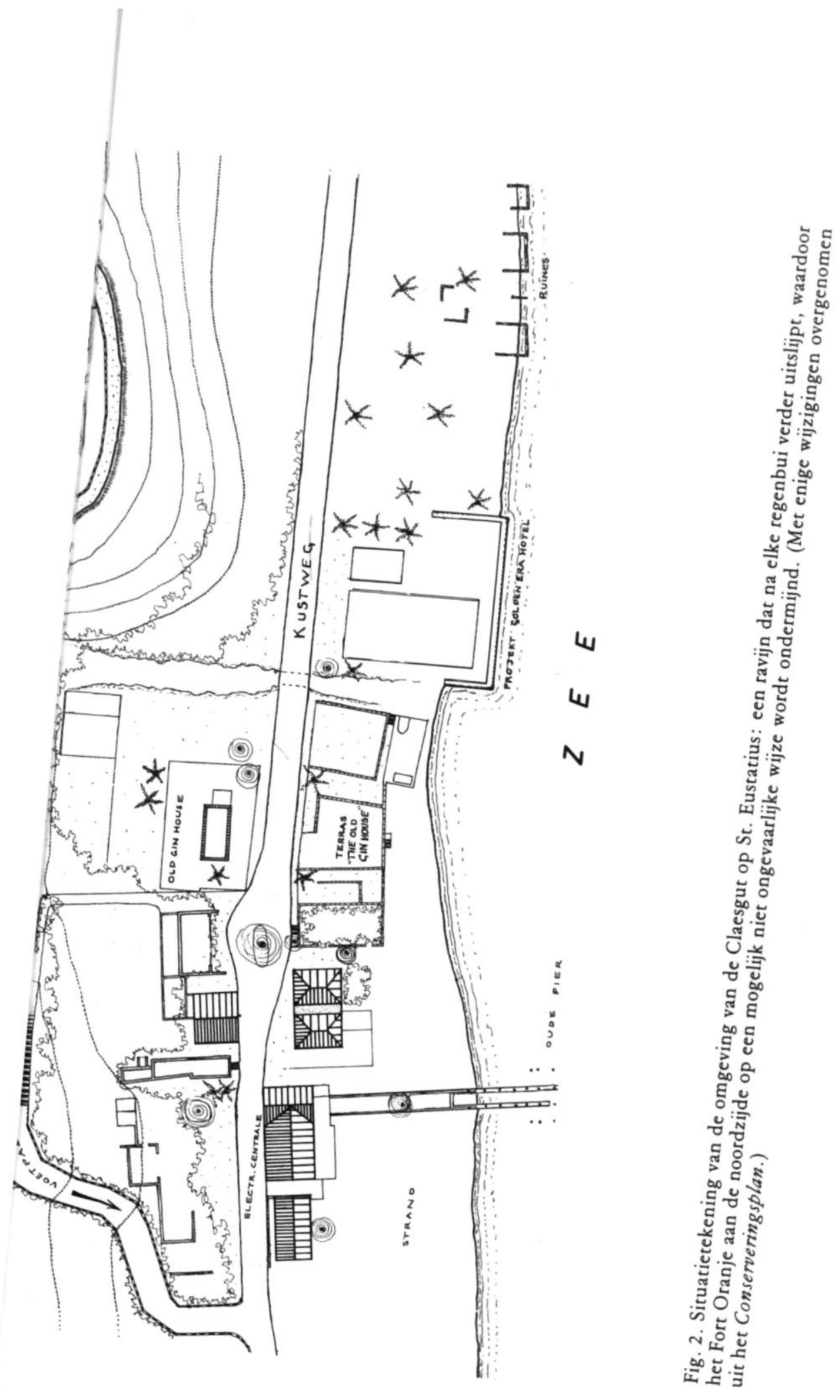
Claesgut landinwaarts gaat, komt in een nauw en diep ravijn omstreeks $60 \mathrm{~m}$ lang, 35-20 m breed en $35 \mathrm{~m}$ hoog - met bijna loodrechte wanden waar het profiel van vele, horizontaal afgezette, zachte vulkanische tuflagen fraai zichtbaar is. Het is hier bladstil en de plantengroei lijkt in niets op de droge, doornige vegetatie buiten (Fig. 5). Achterin de kloof liggen enkele resten van metselwerk, stoepen en afrasteringen, en hoog boven ons zien we, tussen enkele struiken, de meest noordelijke hoek van de borstwering van het Fort uitsteken.

Staande op deze uitstekende plek zien wij ook waar al dit puin vandaan komt: van de huizen aan de rand, van het deel van de Fort Oranjestraat dat vroeger leidde naar R.K. Kerk en het voetpad naar de Benedenstad. Zo gezien lijkt het wachten slechts op verdere afstortingen welke binnenkort zouden kunnen volgen (Fig. 3 en 4).

Een van de goede dingen van dit Conserveringsplan is, dat op verscheidene plaatsen de aandacht wordt gevestigd op het gevaar dat een voortschrijdende erosie van de Claesgut voor de er rondomgelegen huizen, de Kerk en vooral het Fort zou kunnen opleveren.

Om de ernst van deze toestand vast te stellen en te komen tot een plan om verdere uitslijting te verhinderen, wordt gepleit voor een onderzoek over de wijze waarop deze bedreiging van het Fort Oranje kan worden verminderd, wellicht door middel van een plan tot regulering van de afvoer van het regenwater en tot versteviging van de gutwand.

Moge het denkbeeld van een Amerikaan om van de Claesgut een winkelcentrum met liften te maken al ongeloofwaardig klinken, haast ongelooflijk is het dat nog steeds niets werd gedaan aan de iedereen toch al jaren lang duidelijke wenselijkheid het uit de stad stromende regenwater de Claesgut niet nòg verder te laten vergroten.

Alleen nadat in deze orde op zake is gesteld en de veiligheid ter plaatse is verzekerd, zou men kunnen denken aan het in het Conserveringsplan gedane voorstel "het voetpad naar de Benedenstad weer te herstellen door middel van een (houten) voetgangersbrug langs de korte zijde van de Claesgut", om de toeristen behalve een indrukwekkend uitzicht ook de nodige griezels te kunnen bezorgen.

Begrip voor de ernst van de toestand was er ook bij de Adviesraad voor culturele samenwerking tussen de landen van het Koninkrijk, toen deze op zijn 14de zitting (Curaçao, 17-24 april 


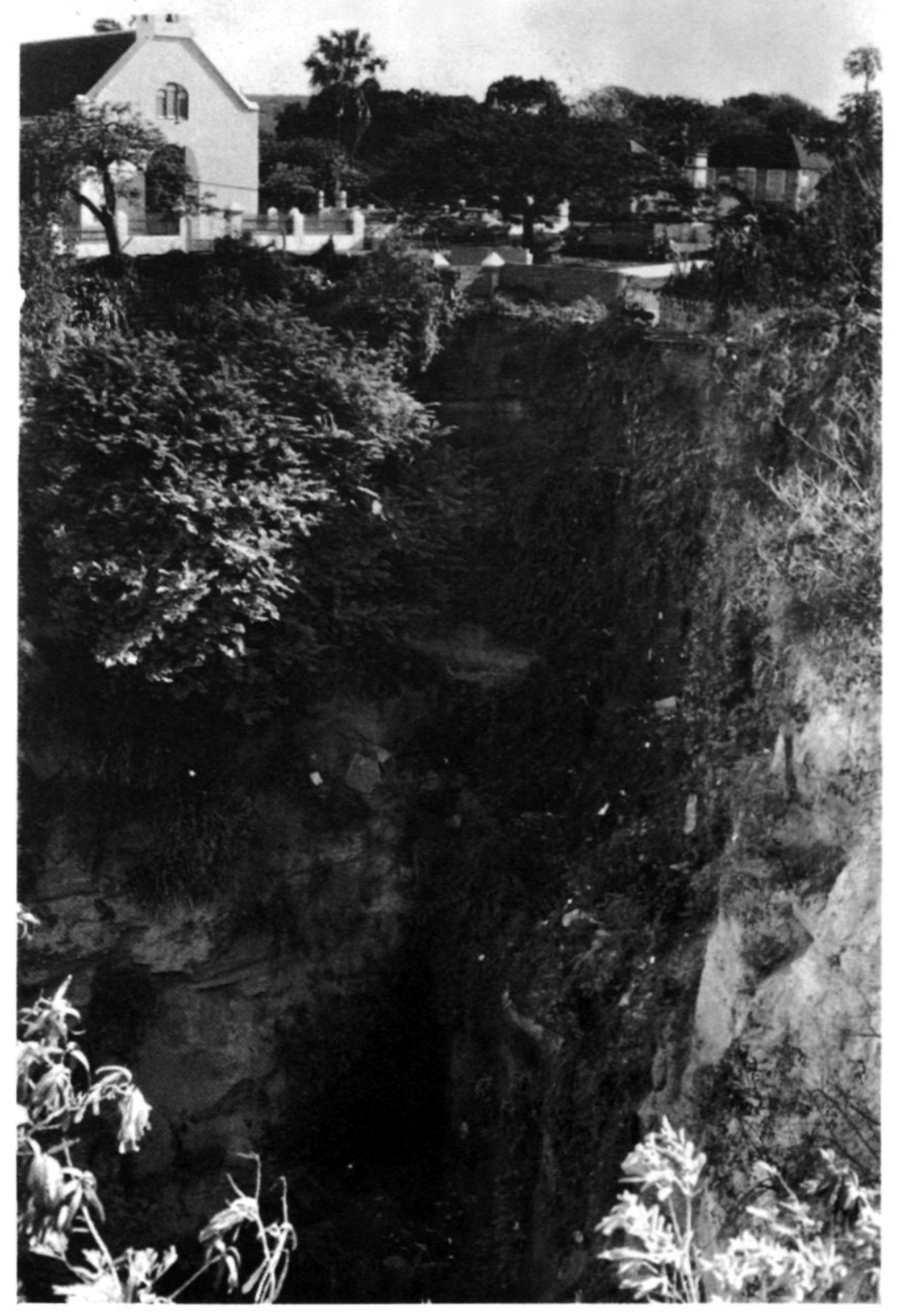

Fig. 3. De oostwand van de Claesgut op St. Eustatius, gezien vanaf de noordpunt van Fort Oranje welke boven de ca. $50 \mathrm{~m}$ diepe afgrond uitsteekt, in de richting van de R.K. Kerk en de Damsteeg. (13.VII.1973) 


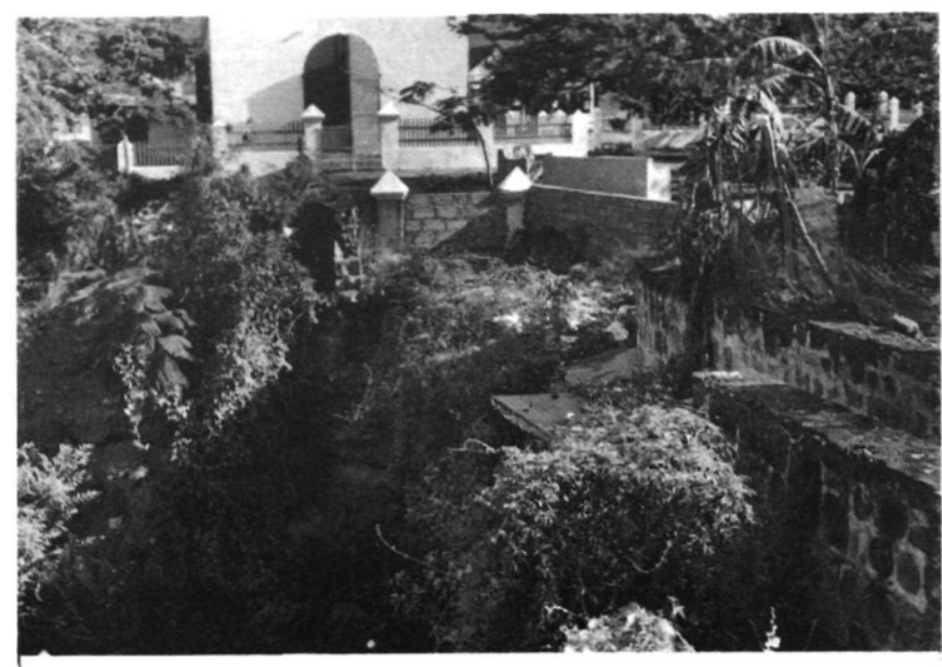

Fig. 4. De noordoostrand van de Claesgut, met overblijfselen van het deel van de Fort Oranje Straat dat vroeger leidde naar het voetpad naar de Benedenstad, gezien in de richting van de R.K. Kerk. (13.VII'73)

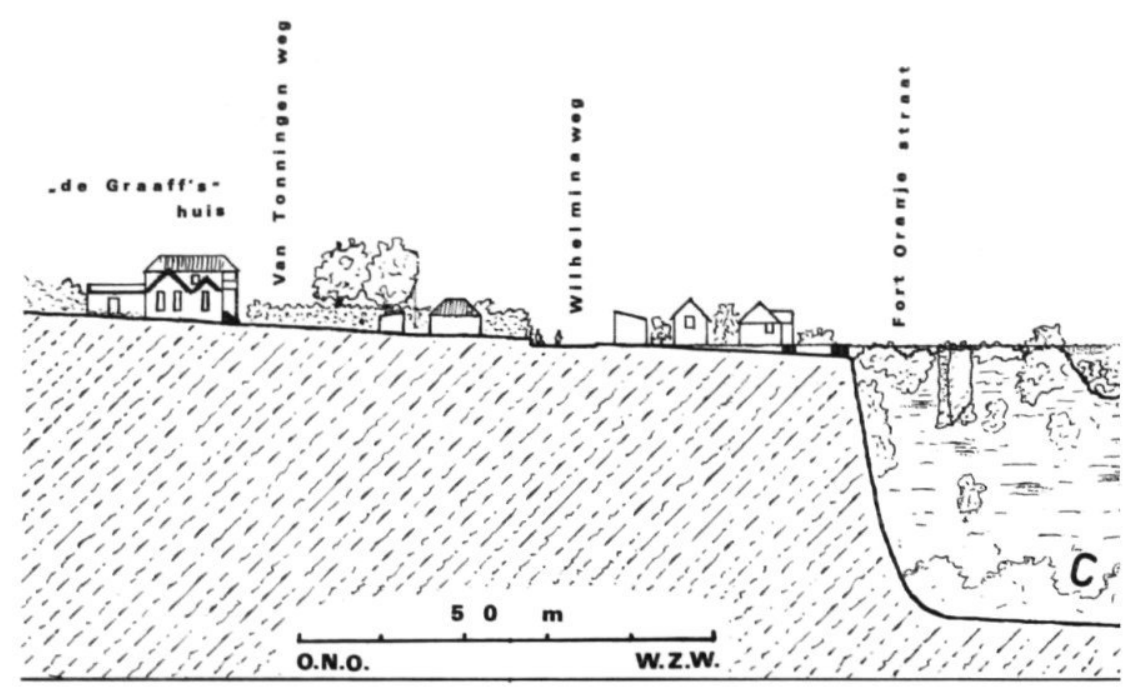

Fig. 6. Een profieltekening van de Claesgut en omgeving op St. Eustatius, in hetzelfde gebied dat in Fig. 2 werd afgebeeld. Op de steile wand onder Fort Oranje werd de begroeiing en de horizontale gelaagdheid van het tuflagen 


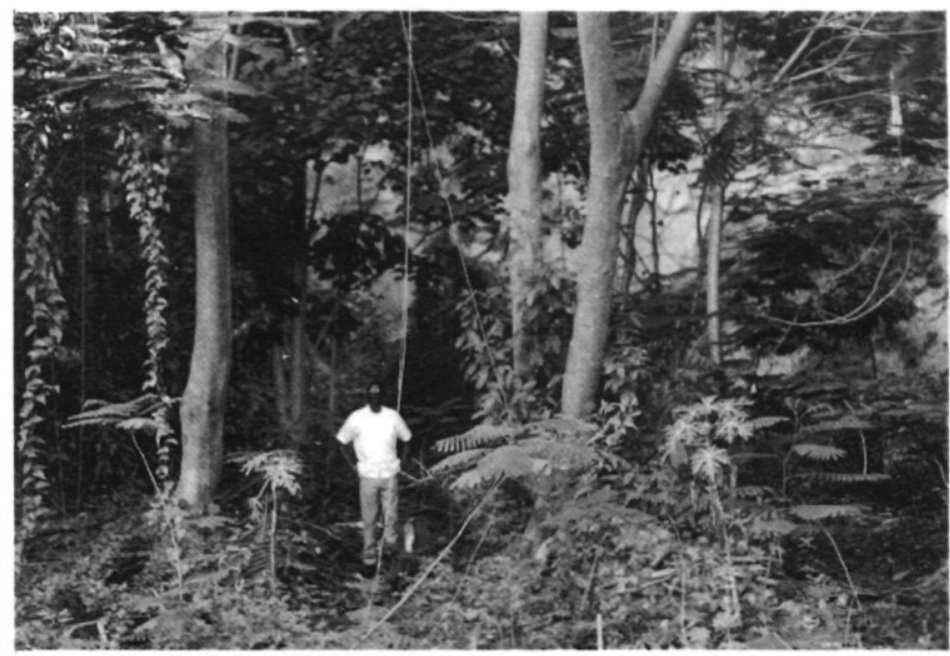

Fig. 5. Op de bodem van de Claesgut, waar zich dankzij de windstilte en de betrekkelijke vochtigheid een vegetatie heeft ontwikkeld welke aan die van de krater van de Quill doet denken. (13.VII.'73)

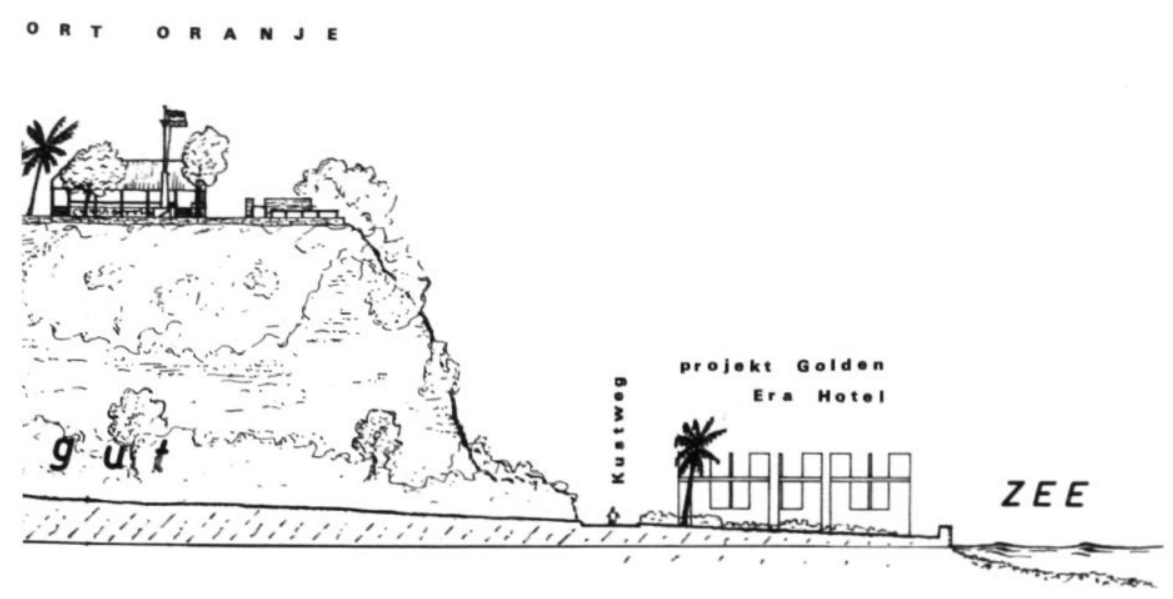

zwakjes aangeduid. (Met enkele veranderingen overgenomen uit het Conserveringsplan.) 
'74) met betrekking tot de restauratie van Fort Oranje van mening was, dat op korte termijn maatregelen moeten worden getroffen "teneinde te voorkomen dat delen van de borstwering door het water worden ondermijnd en weggevoerd".

\section{Naschrift}

De Amigoe van 4.IX.'74 meldde dat een depressie welke van Guadeloupe via St. Kitts naar Puerto Rico trok in een paar uur tijd 105,7 mm water heeft doen vallen op een uitgedroogd St. Eustatius. 'Claesgut het laagste punt van Oranjestad kreeg het ook nu weer zwaar te verduren. Vanaf vijf verschillende kanten stroomde het water met zo'n geweldige kracht naar deze natuurlijke afwatering toe, dat de beschermmuur van de Claesgut het begaf en over de gehele breedte van de weg ruim zestig meter naar beneden stortte. . . . Een ijzeren hek, dat 's morgens nog bovenstond werd de volgende morgen aan de kust gevonden. In de Fort Oranjestraat werden twee auto's door de stroom meegesleurd.' 